\title{
Checking Effective Factors and Presenting the Framework for Customer Relationship Management in Hospitals in Iran
}

\author{
Reza Samizadeh $^{1} \&$ Niloofar Nikoo ${ }^{1}$ \\ ${ }^{1}$ School of Engineering, Alzahra University, Tehran, Iran \\ Correspondence: Reza Samizadeh, School of Engineering, Alzahra University, Vanak Street, Tehran, Iran. Tel: \\ 98-912-111-6695. E-mail: rsamizadeh@alzahra.ac.ir
}

\author{
Received: August 15, 2012 Accepted: September 27, 2012 Online Published: October 26, 2012 \\ doi:10.5539/emr.v1n2p163 URL: http://dx.doi.org/10.5539/emr.v1n2p163
}

\begin{abstract}
Rapid progress in communication and information technology and fierce competition in hospitals to attract and retain customers has led to concept of customer relationship management. Hospitals today possess the most significant factor in health care system and play an important role in people's health maintenance. CRM's noticeable improvement in a hospital can include immediate access to patient's record, prompt response to patient's appointment and patient's immediate admission, timely review of complaints, and flexibility in service delivery to patients. Patient's satisfaction is the ultimate key in maintaining profitability of hospitals. The purpose of this study is to find effective factors and presenting a framework for customer relationship management in hospitals in Iran. Thus, it examines the framework and factors in patient's satisfaction in hospitals.
\end{abstract}

Keywords: communication, information technology, customers, hospital, customer relationship management

\section{Introducation}

\subsection{Definition of Customer Relationship Management}

CRM is an acronym for Customer Relationship Management. By employing CRM, customer relationship with organization and their requirements are fundamentally reviewed and analyzed. CRM in fact is a process to collect and integrate information in order to employ and use them more effectively. This information can be in relationship with customers, sales, effective marketing, and/ or marketing needs.

Customers contact organization through Internet Web sites, phones, sales centers, distributers, and network of partners. CRM main task is to facilitate communication between the organization and customers (with their preference) with no limitation in time, place and nationality such that customers feel that he is in contact with a single organization that knows him, value his opinion and can answer his needs with fastest method of communication.

Following are some definitions of CRM:

- Customer Relationship Management is a business strategy that integrates internal processes, their functions, and external networks to add value to customers through use of customer related information and information technology (Buttle, 2004).

- Customer Relationship Management is a process that manages the relationship with the current customers and a selection of newer customers in order to increase their loyalty and profitability (Tiwana, 2001).

- Customer Relationship Management is an investment approach to understand customers and impact their behavior through a meaningful relationship to a higher customer acquisition, retention, loyalty, and profitability (Swift, 2001).

- Customer Relationship Management is a one to one marketing that uses computer technology to develop and manage customer relationship with the organization (Pepers \& Rogres, 1997).

- Customer Relationship Management is a strategic approach that integrates process, technology, and people in order to better understand organization customers, increase stakeholders profitability, and establish a long term profitable relationship with customers (Almotairi, 2009).

1.2 Checking Some Framework in Customer Relationship Management

In the framework presented by Weiner in 2001, effective factors in implementation of customer relationship 
management are introduced as follows:

Customer Database Bank: A necessary first step required for customer relationship management is construction of database bank. This step is the foundation for any CRM activity. Information should be available in any given time.

Data Analysis: Database bank is analyzed to classify customers.

Customer Selection: Customers selection can be accomplished after construction and analysis of database bank. Decision in a service provider place like a hospital is made mostly based on patients visits. The purpose of data analysis in customer selection is to separate customers with higher long term profitability from those that are currently hurting profits

Customer Targeting: Mass marketing approaches such as television, radio and print advertising are appropriate for public awareness and achieving other objectives. However they perform poorly for customer relationship management due to their nature. Rogres and Peppers have urged companies to begin to establish a direct relationship with customers rather than using mass media. One to one marketing means using the technologies to help organization to build individual relationship with customers.

Relationship with Preferred Customers: The purpose of relationship program is to raise customer satisfaction more than competitors.

Confidentiality issues: Two confidentiality issues were examined:

Opt-in Option - Internet web users must consent to the collection and use of personal information

Opt-out Option - If not satisfied, customers be able express their opposition

Measuring Success Rate of CRM: In this step costs for new customer acquisition, conversion of potential customers to active customers, customer retention, maintaining costumer loyalty and customer participation must be calculated.

This model implies that managers should have sufficient knowledge of customers and know how to use the information to develop a complete CRM prospect. In this model several crucial components of CRM is expressed. There is also emphasis on importance of database which contains customer significant data such as, interaction and transactions, customer contacts, expressed information, and response to marketing stimulus (Winer, 2001).

Gartner and other 2001 experts believe customer relationship management is type of strategy that maximizes profit, revenue, and customer satisfaction through following. Gartner uses 8 steps to design such an approach.

Develop Organization Vision: Creating an image of what organization wants to look such that its competitive market position based on premises of its proprietary, brand and delivery can be created.

Develop CRM Strategy: In this stage customers focused objectives and resources required to achieve those objectives are determined.

Valued Customer Experience: In this stage need to insure that organization products and customer interactions continuously creates values for loyal customers.

Facilitate Organizational Collaboration: Organizational collaboration describes changes in organizational culture, structure, and behavior to ensure that employees, partners, and suppliers collaborating together to create values for customers.

Re-engineer Business Processes: Customer approach to business processes will have possible impact on many practical organization programs. The key to this is making decisions what processes can create opportunities for organization's differentiation and at the same time present values to customers.

Develop Customers Information Strategy: The purpose of this stage is to collect accurate information and forward them to appropriate department. Sharing customer information within an organization should be part of a logical strategy.

Use of Technology: The purpose of this stage is management of available data and information, providing practical interface programs for customer's interaction, and reshaping of IT infrastructure and architecture.

Measuring Metrics: The purpose of this stage is to measure the internal and external indicators of success and failure of customer relationship management system.

These indicators have following application: 
- $\quad$ Set and measure goals for customer relationship

- $\quad$ Receive and apply feedbacks to improve customer relationship management strategy

- Monitor customer experience of the organization

- $\quad$ Modify the practice of employees compensation and incentives

- $\quad$ Assess organization current position against competitors

From Chen and Popvich perspective, customer relationship management is a combination of technology, processes, people and strategy seeking to understand company's customer. It is an integrated approach to manage relationship by focusing on customer retention and relationship development.

Technology: Customer relationship management application program is benefited from information technology and its ability to collect and analyze customer data, interpret customer behavior, develop predictive models, timely response and effective communication, and deliver service and product to customers. Data warehouses, human resource planning systems, and Internet are also infrastructures to CRM applications.

Business Process Changes: Retention of current customers has greater profitability than building new relationships. Customer oriented approach targets product development and service delivery to answer customer needs and its purpose is to increase revenue, enhance customer's loyalty, reduce the cost of sales and service, and improve operation.

People: As long as technology and business processes are essential to the success of CRM projects, personnel and employees are considered building blocks of CRM.

Strategy: Implementing CRM program requires vision and all personnel and employees must understand the purpose and changes that CRM will bring (Chen \& Popvich, 2003).

In the model presented by Adrian Payne and Pennie Frow, effective elements to implement customer relationship management are described as follows.

Strategy Development Process: This process should focus on organization business strategy and customer strategy.

Value Creation Process: Process of value creation transforms the output of strategy development process into programs that both extract and deliver value. The value creation process consists of three key elements:

- Determining what value the company can provide to its customers

- Determining what value the organization receives from its customers

- Managing the exchange of values between customers and the company to maximize customers lifetime value

Communication Channels integration process: Process of integrating communication channels transforms the output of business development strategy and value creation process to value added activities.

Information Management Process: Collection, use, examination of customer data and information from customer contacts are part of information management process to generate customer insight and appropriate marketing. Key elements of information management process consist of data warehouse, information technology system, and analysis tools.

Performance Assessment Process: This process consists of two components. 1) Shareholder results, 2) Performance monitoring (Payne \& Frow, 2005).

CRM is typically implemented in essential and operational environment like service, sales and marketing.

According to Hahnke CRM consists of three cycles. First phase, CRM lifecycle begins with integration of front office data and centralization of customer related data. Second phase, analysis is most vital to CRM success. CRM analysis effectively provides management of customer relationships. Third phase is where strategic decisions are implemented. Business processes and organizational structure are corrected based on improved customers understanding obtained through analysis. These processes closes CRM loop and allow organization to receive valuable insights gained through analysis.

This framework consists of 6 processes of review and analysis, creating vision, building business cases, planning and problem solving, implementing and integration, and value analysis. Three key elements of CRM, people, process and technology comprise these 6 processes.

Accelerated SAP methodology is a proven, repeatable and successful method to implement in organizations that are in contact with customers. ASAP consist of project preparation phase, business plan, realization, final preparation, and implementation and support. 
Project Preparation: The main goal in this stage includes project initial planning, scheduling, identifying project goals, and staffing. The output of this phase is to design and plan the project and to organize project team.

Business Plan: The purpose of this stage is to identify and document business requirements and processes to set up ground work for remaining steps.

Realization: The purpose of this stage is to implement all business processes based on defined goals.

Final Preparation: Departments final preparation, employees final training, system management, and ....... If done successfully, the organization will be ready to implement SAP system.

Implementation and Support: After completion of all above stages, SAP system can be implemented in organization. After implementation, processes review and continuous improvement will be executed.

\subsection{Customer Relationship Management in Hospital}

In order to build a trust bridge between hospitals and patients, today hospitals in many countries are seeking to implement customer relationship management. Since more than $80 \%$ of their business involves patients, we realize the importance of customer relationship management. Customer relationship management is a rational goal of any organization including hospitals. By applying customer relationship management system, hospitals can recognize three groups of needs, including identifying requirements, access to patient satisfaction, and providing ground for patient education. CRM enables departments to obtain patients necessary information and use them efficiently (Yina, 2010). For service providers in a hospital, customer relationship management is an approach to learn about their patients, establish relationship, provide timely information, and track their results (Benz \& Paddison, 2004). In today's world CRM is used in many industries such as banks and finical centers and manufacturing industries. Nevertheless, hospitals due to differences with other organization in terms of patients' expectations and their limitation in choice of treatment are less likely to consider CRM.

Contrary to other service providers where customers who willingly receive service and gladly pay for that, patients in a hospital are customers because of their illness and do not pay willingly. On the other hand, in a hospital unlike other organizations the possibility of patients contacting other departments like ambulance, reception, doctors, nurses, finance, and so on ...exists. Hence, hospitals need to be aware of this dissimilarity with other organizations when dealing with patients.

In a hospital every interaction that a patient has with various departments is crucial and can factor in patient decision to choice that hospital in the future.

\subsection{Patinet Satisfaction in Hospital}

According to customer satisfaction definition, customer satisfaction in a hospital is essentially patient's mental state. It is defined as hospital's ability to meet patient's expectations. When a hospital exceeds meeting patient's demands, patient is overly satisfied and when a patient feels happiness in his heart, he is reluctant to change hospital. Many countries and international organization have adopted provisions in medical fields to raise patient safety standards. To accomplish this, health care provider must incorporate safety and quality into their organization to assure appropriate clinical and administrative activities (Naveh \& Stern, 2005).

Stephen Walston suggests three important factors in a hospital climate for maintaining patient safety and sustaining their satisfaction.

Manager's support: One of the key factors for patient safety and satisfaction is mangers ability to administer and support employees to develop, prioritize, and implement appropriate strategy. Since managers are ultimate decision maker, their management and support plays major role in patient safety in every department of hospitals. . They assign employees responsibilities based on their activities and goals and define each employee's position.

Reporting System: A good reporting program is considered one of the patients' safety factors in a hospital. To improve patients condition requires correcting errors in a reporting program.

Adequate Resource: Patients safety in a hospital is also achieved through adequate resources such as information technology and qualified staff. Information technology in a medical field contributes to lower human errors and assist health care providers to produce higher quality service and greater workload (Walstone, 2008).

In another study, Andaleeb introduced important and influential factors in customer satisfaction in hospitals as follows:

Communication with Patients: His research indicates that communication with patients can have significant impact on their treatment. If patients feel resentment, ignorance, and unsafe, they have longer treatment and 
consequently lower satisfaction.

Competence of Staff: Anadeelb in his research has reached conclusion that doctors qualifications influences patients decision and his evaluation of hospital.

Hospital Facilities: The availability of modern equipment, housekeeping, and in general the feeling that facilities are in good condition will increase patients content.

Staffs Demeanor: In businesses where there are contacts with customers, employees demeanor in various departments have significant impact on customer satisfaction.

Perceived Costs: Customers satisfaction can also be affected by cost of treatment received by hospital. If hospitals costs exceed patients expectation, it will influence their satisfaction (Andaleeb, 1998).

In 2011, Roger studied factors impacting patient satisfaction in hospitals. He introduced four influential factors of communication, type of communication, environment of facility, and waiting time.

Communication: Patients communication with doctors and staff to gain access to their treatment and conditions is a key factor in their content. Good communication reduces stress and anxiety in patients.

Sincere Relationship: Research has indicated that since illness reduces patient's independency, staff's courteous and friendly demeanor not only restores patient's health but is also necessary for patient's satisfaction from hospital treatment.

Environment of Facility: Patient's first impression of a healthcare facility arrives from its appearance. Creating an appropriate environment can be significant for three reasons:

Creates an opportunity to meet patients need

Boosts the spirit and morale of patients and staff

Adds a positive attribute to hospital

Waiting Time: Delay in receiving services will result in customer's dissatisfaction and resentment. The problem of waiting time will intensify with lack of service and justification (Atinga, 2011).

\subsection{General Problems of Hospitals in Iran}

Generally hospitals in Iran are divided into two categories, private and public hospitals. Public hospitals are governed by public organizations like medical universities, social security organization, army and ministry of oil, etc. Beside, private hospitals have been established by some financiers. During pulls, there are some difficulties and problems in both hospitals. Surveys show that clients are not satisfied with the services received. High tariff, not covering the insurance, inappropriate behavior toward patients and their relatives, not accepting emergency patients due to the lack of enough funds, shortage of hospital beds, inappropriate number of patients with features, limited funds and recourses, closing the clock pharmacies, transferring ambulances to private sectors and obtaining illegal funds outside the hospital bill are parts of difficulties and frustration that patients deal with. Among them, the shortage of particular beds is one of the major problems that applicants for public hospitals face with. In addition, patients in public hospitals suffer from the shortage of CCU and ICU beds. Being unrealistic rates of hospital health system causes problems in maintaining and managing in public hospitals. The quality of treatment is greatly affected. In comparison with private hospitals, conditions are generally different. There are ideal conditions for patient reception, but only less than $40 \%$ of patients go to private hospitals due to exorbitant fees and the lack of the coverage of insurance.

\section{Method}

\subsection{Checking the Common Elements of the Framework in Hospital}

Five key elements of strategy, process, people, technology, and indicators with continuous improvement encompass factors of the framework in hospital.

Strategy: Effective factors in the element of strategy consist of following:

- Organization's Vision

- Organization's Mission

- Project Definition for all Sectors

- Support of Senior Management

- Funding and Resource Planning

- Sectors Interest and Their Perspective of Project Implementation

When reviewing the strategy element in a hospital, attention should be given to organization's vision and mission 
as, whether organizational processes follow the same direction, whether funding and resource needed to implement CRM are considered, and whether senior management prepared required staffing and have necessary collaboration with project team.

In element of strategy should pay attention to hospital strengths and weaknesses. By using SWOT matrix, strengths and weaknesses, opportunities and threats are identified.

Absense of a strategic framework to implement CRM is one of the reason for CRM project failure.

Process: Effective factors in element of process consist of following:

- Directing the processes in line with patient's demand

- Type of relationship between doctor and patient and his family

- Correction of errors in reporting program

- Ensuring complete health of patients before hospital's discharge

- Providing pleasant environment and service upon reception

- Patient's waiting time on admission

- Staff's communications on admission

- Providing patients required medication by hospital

- Providing laboratory facilities and their periodical inspection

- Compliance with patient's environmental and personal hygiene

- Hospital's contact after patient discharge

- Contact with discharged patient and use of his experiences

Customer relationship management is a strategy within an organization that aims to create and establish long term relationship with customers, hence customers related processes should be analyzed, remembering that type of process depends on type of business.

The major process in all hospitals is to improve patient's health. Other processes are also directed to follow same course.

Processes in a hospital are divided into three categories of patient's admission process, patient's treatment process, and patient's minor processes.

Today with increased level of awareness of people to health and treatment issues in one hand and rise in number of service provider centers in other hand has led patients to have broader range of options in treatment. Hence in a world of centralized competition, only those hospitals with more efforts in providing service with higher quality and capable of directing processes in line with patients demand can succeed.

People: Effective factors in element of people consist of:

- Degree of commitments of top level managers

- Staff training and familiarization with project objectives

- Staff training for communication with patients and their family

- Staff training for changing their culture to patient oriented approach

- Ensuring staff working competences

- Implementing incentive and punitive programs

Organization, to achieve its goal should see its employee as its assets and take necessary actions to inform, educate, and motivate them. Persons working in a hospital including doctors, nurses, finance and administrative personnel are hospital staffs. Quality of their work will impact patients' satisfaction, and can be effective in patients acquisitions. Lack of employees' motivation to accept change, resistance to change, and fear of job loss are issues that need to be considered. So by creating a workshop to teach communication with patients, ensuring the competence of staff, creation of incentive and punitive programs, motivating employees and review of their performance can improve conditions and raise the level of patient's content.

Technology: Effective factors in element of technology consist of:

- Use of integrated information system(Hospital Information System)

- Use of dataminig to extract knowledge

- Use of CRM software

- Establishing communication channels

- Creation of Intelligent Patient Records

- $\quad$ Staff use of internet

Today, various organization use information technology to administer tasks, gain competitive edge, and reduce 
costs. Health care providers are not an exception to this. An integrated and comprehensive system to record information helps noticeably. The comparative findings between two manual and automated information system of a hospitals shows that using information system impacts processes and considerably reduces the length of time patients stay in the hospitals and consequently improves hospital performance. Hospital's use of information technology also improves health care quality and medical prescription resulting in lower medical errors.

For any organization or firm especially organizations like hospitals, installing CRM software to achieve maximum profitability and efficiency and to retain and attract customers is considered essential. Hospital can use CRM application programs to reduce costs and to automate their operations to run more efficiently.

CRM software should be installed based on hospitals information system (HIS) with the goal of data integrity obtained from medical activities. HIS output is used by CRM to strengthen and maintain patients' relationship with hospitals. Since most data needed for CRM is provided by HIS, for optimum usage of CRM, it should be integrated with information systems. This integration leads to an awareness of customer needs and higher customers satisfaction.

Use of widespread communication channels such as Internet, fax, email, telephone... and their integration can be effective in serving patients.

Hospital's information is growing, so is the need for a tool for data analysis and extraction of knowledge. Analyzing medical information enhances and improves health care with better performance.

Data mining process is an effective mechanism to generate local medical knowledge, to select best possible diagnosis and treatment, to find causes of epidemics, to extract medical errors, to predict illness of someone with certain disease, and...

Indicators with Continuous improvement: Effective factors in element of indicators and continuous improvement consist of:

- Indicators to review performance of departments

- Indicators to review performance of staff

- Indicators to review performance of organization based on vision

- Indicators to measure satisfaction level of patients

Indicators to assess processes

Assessing quality of service is not as easy as assessing quality of produced goods. Nature and characteristic features of service makes its evaluation difficult. These features include 1) intangibility, 2) changeability, and 3) not experienceable.

Organizational performance evaluation include: Evaluation of strengths and weaknesses of the organization based on indicators, criteria, and specific standards in a specific period to determine deviation and take corrective actions. Without evaluation and access to progress report and objectives and without identifying the challenges facing the organization, continuous improvement of performance will not be achieved. Thus, organizational performance assessment not only provides a comprehensive picture of organizational performance, rather it can also identify strengths and areas of improvement and eventually provide access to continuous quality improvement.

In a hospital, indicators for assessment of various departmental performances can be defined. Indicators related to patients can be defined as indictors identifying their satisfaction level, loyalty, decline in number of patients, and customers' complaints.

Strategy indicators can be defined as growth, and expense rate, and process indicators as time of delivery of service to patients, process deviation from actual value, mortality rate, and patients' admission to the hospital.

\subsection{The Proposed Framework}

After examining the factors and interview with the experts and preparation and distribution of questionnaires in hospitals and among experts, some of the factors were eliminated due to existing conditions in Iran. The remaining factors are introduced in the form of a framework. The proposed framework is based on five elements of strategy, process, people, technology, and indicators with continuous improvement. In any organizations, strategic issues are at the helm. Issues like prospect, mission, and, planning resources and budget take place at the beginning. Patients communicate with hospital through different channels. These channels are integrated with each other and all related information is kept in hospital information system and Individuals and hospital 
staff in all departments have access to this information. On the other hand, hospital staff is the main supplier of triple processes in the hospital that include the reception, treatment and secondary process.

At the end of the framework, is being the indicator and continues improvement element that evaluate pros and cons in hospital. This element is associated whit other elements, take the information and feedback to them.

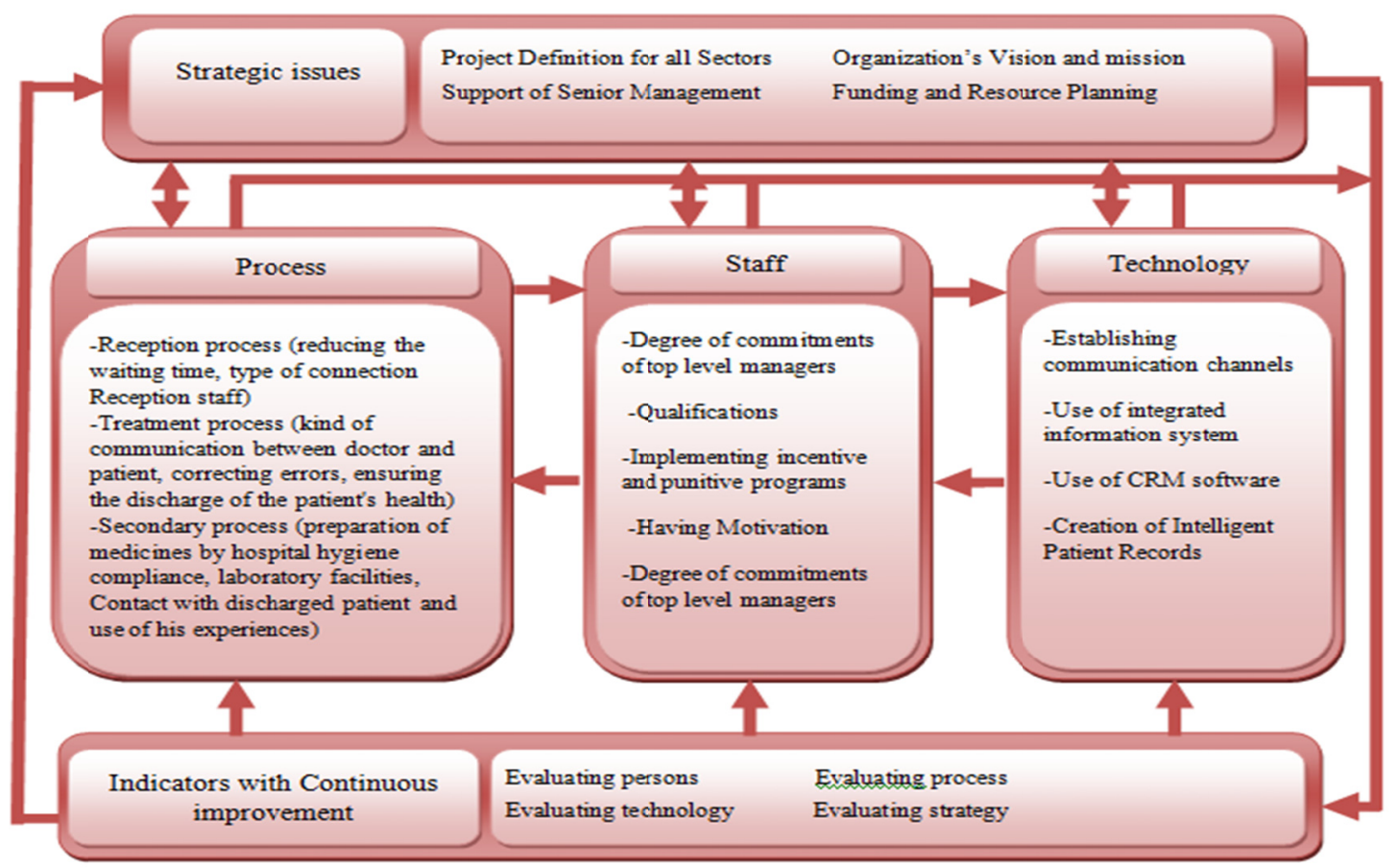

Figure 1. The proposed framework for customer relationship management in hospital

\section{Results}

\subsection{Conclusion and Results}

Today, there are many reasons to implement customer relationship management in organizations. Some of the reasons are improved customer satisfaction, customer retention, reduced costs, and customer acquisitions. Such organizations are hospitals.

Hospital is a place where patients are bound to receive services. But nevertheless among various hospitals they can choose a hospital where other patients have better experiences. Since hospital's main income is based on patients' visits to the hospital, actions can be taken to attract more patients. One of these actions is to implement customer relationship management not as a technology tools but rather a means to acquire and retain customers.

Customer relationship management in hospitals is a mechanism for service provider employees to learn about current and potential future customers so they are able to communicate, provide timely information, follow up the results, and respond timely to their needs.

This study examines effective factors on framework for customer relationship management in hospitals in a framework. Since these factors vary in countries with different culture and background and purpose of this paper is to study customer relationship management in Iran, therefore a few local factors that raise patient satisfaction in hospitals in Iran was also considered. For example providing medications for patients and numerous problems in hospital's reporting systems are some of difficulties hospitals facing in Iran that need attention.

Two state and educational training hospitals were chosen to study these factors. Choice of private hospitals considering the president's and management's authority would certainly attain different results. Unfortunately, due to restrictions and lack of cooperation of private hospitals, access to their data was denied and consequently the result of this study is based on state hospitals.

Results of the studies conducted in two Akhtar and Bandar Torkaman's Imam Khomeini hospitals indicate that one of existing problem at both hospitals is lack of required budget and resource availability. Unfortunately, in many cases state hospitals due to budget shortage and low tariff for doctors are not able to provide hospitals necessary requirements. Lack of necessary budget in both hospitals has also created problems to provide hospital 
equipments. Nevertheless both hospitals have been able to manage providing the equipments.

Among the actions that both hospitals should take in order to raise patient satisfaction is to synchronize the processes with patient needs. In other words re-engineering of the processes is required which has been considered in recent years. To improve hospitals conditions, further evaluation of reporting systems, reducing admissions waiting time, providing patient's necessary medications, contacting discharged patients, use of CRM software, electronic and internet filing, establishing patient satisfaction indicators, and establishing hospitals performance indicators based on defined vision can be effective. However immediate attention should be given to budget preparation in state hospital.

\section{Acknowledgements}

This research project would not have been accomplished without the endorsement of many people, the author is heartily thankful to his beloved family for their understanding and boundless love, through the duration of his studies.

\section{References}

Almotairi, M. (2009). A framework for successful CRM implementation. European and Mediterranean Conference on Information System.

Andaleeb, S. (1998). Determinants of customer satisfaction with Hospitals: a managerial model. International Journal of Health Care Quality Assurance, 11(6), 181-187. http://dx.doi.org/10.1108/09526869810231541

Atinga, R., Abekah-Nkrumah, G., \& Domfeh, K., (2011). Managing healthcare quality in Ghana: a necessity of patient Satisfaction. International Journal of Health Care Quality Assurance, 24(7), 548-563. http://dx.doi.org/10.1108/09526861111160580

Benz, G., \& Paddison, N. V. (2004). Developing patient-based marketing strategies, Healthcare. Executive, 19(5), $40-42$.

Buttle, F. (2004). Customer Relationship Management, Concept \& Tools.

Chen, I. J., \& Popvich, K. (2003). Understanding Customer Relationship Management (CRM): People, Process and Technology. Journal of Business Process Management, 9(5), 672-688. http://dx.doi.org/10.1108/14637150310496758

Naveh, E., Katz-Navon, T., \& Stern, Z. (2005). Treatment errors in healthcare: a safety climate approach. Management Science, 51(5), 948-961. http://dx.doi.org/10.1287/mnsc.1050.0372

Payne, A., \& Pennie, F. (2005). A Strategic Framework for Customer Relationship Management. Journal of Marketing, 69, 167-176. http://dx.doi.org/10.1509/jmkg.2005.69.4.167

Peppers, D., \& Rogres, (1997). Enterprise One to One: Tools for Competing in the Interactive Age. New York: Doubleday.

Ricardo, C. (2005, September). Methodology for customer relationship management. Journal of System and Software, 1015-1024.

Swift, R. S. (2001). Accelerating Customer Relationship: Using CRM and Relationship Technologies. Prentice Hall New Jersey, Upper Saddle River.

Tiwana, A. (2001). The Essential Guide to knowledge Management e-business and CRM Application. Prentice Hall, NY.

Walstone, S., Al-Omar, B., \& Al-Mutari, F. (2008). Factors affecting the climate of hospital patient safety A study of hospitals in Saudi Arabia. International Journal of Health Care Quality Assurance, 23(1), 35-50. http://dx.doi.org/10.1108/09526861011010668

Winer, R. S. (2001). A Framework for Customer Relationship management. California Management Review, 43(4), 89-105. http://dx.doi.org/10.2307/41166102

Yina, W. (2010). Application of Customer Relationship Management in HealthCare, Second International Conference on MultiMedia and Information Technology. 